\title{
Evaluating the Wear of Polycrystalline Diamond Compact Drill Bit Cutters using Indentation and Scratch Tests
}

\author{
Rafid K. Abbas ${ }^{1}$ and Ali Hassanpour ${ }^{2}$ \\ ${ }^{1}$ Department of Chemical Engineering, Faculty of Engineering, University of Al-Qadisiyah, Al-Diwaniya, 58002, F.R. Iraq \\ ${ }^{2}$ Institute of Particle Science and Engineering, School of Chemical and Process Engineering, University of Leeds, LS2 9JT, \\ United Kingdom, England
}

\begin{abstract}
Polycrystalline diamond compact (PDC) drill bits are widely used in oil and gas drilling. The wear of PDC cutters is a major problem during drilling. It leads to severe time losses which affect the overall drilling operation cost. Therefore, it is essential to evaluate the wear tendency for these cutters using predictive approaches. The present research is focused on studying the wear mechanisms of PDC cutters and the effect of their mechanical properties on the extent of wear. The volume of wear for the PDC cutters was determined experimentally using micro- and nanoscratch tests by implementing an approach based on the geometry of the removed material after micro- and nano-scratch tests. The experimental wear results were compared to the predictions from current models in the literature. Various wear models are evaluated for micro- and nano-scratch tests on both layers of the PDC samples. The study shows that the wear of the PDC cutters can be predicted from the material mechanical properties, applied load, sliding distance, and hardness of the PDC cutters. The study could be extended for the evaluation of wear intensity of PDC cutters from various manufactures without using the previous techniques of abrasion testing.
\end{abstract}

Index Terms-Bit wear, Indentation, Micro-scratch test, Nano-scratch test, Polycrystalline diamond compact.

\section{INTRODUCTION}

Drilling for oil and gas is still very demanding in many areas around the world. The use of polycrystalline diamond compact (PDC) bits is widely spread nowadays due to their high performance and durability in harsh environments. Synthetic diamond cutters or inserts that are placed on the PDC bit represent the most significant part of these bits. PDC cutters have significantly increased drill bit efficiency and drilling performance to a point where PDC bits have overtaken tricone bits in many oil and gas drilling

ARO-The Scientific Journal of Koya University Volume VI, No.1(2018), Article ID: ARO.10278, 9 pages DOI: $10.14500 /$ aro. 10278

Received 22 July 2017; Accepted 12 April 2018

Regular research paper: Published 31 May 2018

Corresponding author's, e-mail: Rafid.Abbas@qu.edu.iq

Copyright (C) 2018 Abbas RK, Hassanpour A. This is an open-access article distributed under the Creative Commons Attribution License. applications. Since the first commercial introduction of PDC bits in 1976, many challenges appeared that sometimes halted their applicability, especially in hard geological formations, where abrasive wear and impact damage prevail. Wear of drilling bits is due to macroscopic or microscopic removal or fracture of material, especially at the cutter surface.

Mouritz and Hutchings (1991) investigated the wear rates of the materials used in the teeth of the rotary drilling bits and the abrasive wear mechanisms of these materials. Richardson (1968) showed that abrasive wear rate of any ductile material depended on the ratio of its hardness $(\mathrm{Hm})$ to that of the abrasive (Ha). When $\mathrm{Ha} / \mathrm{Hm}<1$, this means that the abrasive cannot scratch the material and the wear rate is extremely low. However, when $\mathrm{Ha} / \mathrm{Hm}>1.2$, the abrasive can scratch the material and cause high wear rate (Mouritz and Hutchings, 1991). Geoffroy (1999) showed that more than $50 \%$ of the energy of the drilling by PDC bits is dissipated by the wear of cutters under normal drilling conditions, assuming a steady motion and avoiding excessive heating. Fang, et al. (2001) described that the main failure modes of PDC cutters are due to frictional heat and abrasiveness of the rock as shown in Fig. 1.

Tze-Pin, et al. (1992) and Zacny (2012) postulated four primary failure modes of PDC cutters according to the type of wear mechanism: 1 - smooth wear, 2 - microchipping, 3 - gross fracturing or spalling, and 4 - delamination.

Various tests have been carried out on PDC bits and, especially, their cutters to assess their performance and applicability in diverse drilling conditions including harsh environment and high-temperature conditions. Bellin, et al. (2010a) mentioned that the majority of the previous tests are broadly destructive. Abrasion test is the well-known one, where the abrasion resistance of the cutter against abrasive rocks is evaluated. It depends mainly on the hardness of the minerals in the rock. Highly abrasive rocks like granite or hard sandstone are normally used in the abrasion test. The wear of the PDC inserts has been evaluated and reported in the literature (Bellin, et al., 2010a); nevertheless, the precise assessment of the material loss remains a challenge. Therefore, the current study is focused on this topic, that is, determining the wear volume of the diamond layer as well 
as the substrate of the PDC cutters after applying micro- and nano-mechanical testing.

\section{MethodoloGY}

A series of micro- and nano-indentation tests were carried out to determine the mechanical properties of the materials forming the PDC samples. The samples are in the form of cylindrical disks with different dimensions. The images of four PDC cutters that have been used in the experiments are shown in Fig. 2. The specifications of the PDC cutters supplied from two different manufacturers are given in Table I. The upper part of the PDC cutters is made of diamond layer in the form of PDC with cobalt as a binder, whereas the lowest layer (substrate) consists of tungsten carbide embedded in cobalt as a binder. PDC specimens were finely polished to reduce the effect of surface asperities and consequently to reduce the measurement error of hardness and Young's modulus. Furthermore, well-polished surfaces will produce clearer imprints from micro- and nanoindentations and enable better measurements of the diagonals

TABLE I

SPECIFICATIONS OF THE PDC SPECIMENS

\begin{tabular}{lccc}
\hline \hline $\begin{array}{l}\text { Commercial } \\
\text { order }\end{array}$ & $\begin{array}{c}\text { Cutter diameter } \\
(\mathrm{mm})\end{array}$ & $\begin{array}{c}\text { Cutter height } \\
(\mathrm{mm})\end{array}$ & $\begin{array}{c}\text { Diamond thickness } \\
(\mathrm{mm})\end{array}$ \\
\hline M1308 & $13.44( \pm 0.03)$ & $8.0( \pm 0.1)$ & $2.2( \pm 0.2)$ \\
M1313 & $13.44( \pm 0.03)$ & $13.2( \pm 0.1)$ & $2.2( \pm 0.2)$ \\
K1608 & $16.00( \pm 0.05)$ & $8.0( \pm 0.1)$ & $2.0-2.5$ \\
K1908 & $19.05( \pm 0.05)$ & $8.0( \pm 0.1)$ & $2.0-2.5$ \\
\hline \hline
\end{tabular}

PDC: Polycrystalline diamond compact of the obtained indents. Following the above characterization work, micro- and nano-scratch tests were carried out, and the results were compared with the predictions from the wear models in the literature.

\section{EXPERIMENTAL WORK}

\section{A. Micro- and nano-indentation tests}

Micro- and nano-indentation measurements of hardness and Young's modulus of many materials have been performed by numerous researchers; nevertheless, many previous attempts for indenting the diamond layer of the PDC cutter have failed. Many researchers mentioned the failure to be due to the breakage of the indenter, and especially, the Berkovich type (Sumiya and Irifune, 2004). Nevertheless, the use of Berkovich probe was successful under very low loads, that is, $<3 \mathrm{mN}$ (Couvy, et al., 2011). In our work, nano-indentation hardness and Young's modulus of the diamond layer are measured using a Berkovich indenter using the NanoTest machine manufactured by Micro Materials Ltd., Wrexham, UK. A typical load-penetration plot for the indentation is shown in Fig. 3. Hardness and Young's modulus of the sample were obtained using the approach reported in the literature (Couvy, et al., 2011) but at different settings.

After completing the nano-indentation tests of the diamond layer, it is crucially important to check that the Berkovich probe has not been damaged. To do this, nanoindentation tests were carried out on a ceramic sample before and after the indentation process of the diamond layer. It was observed
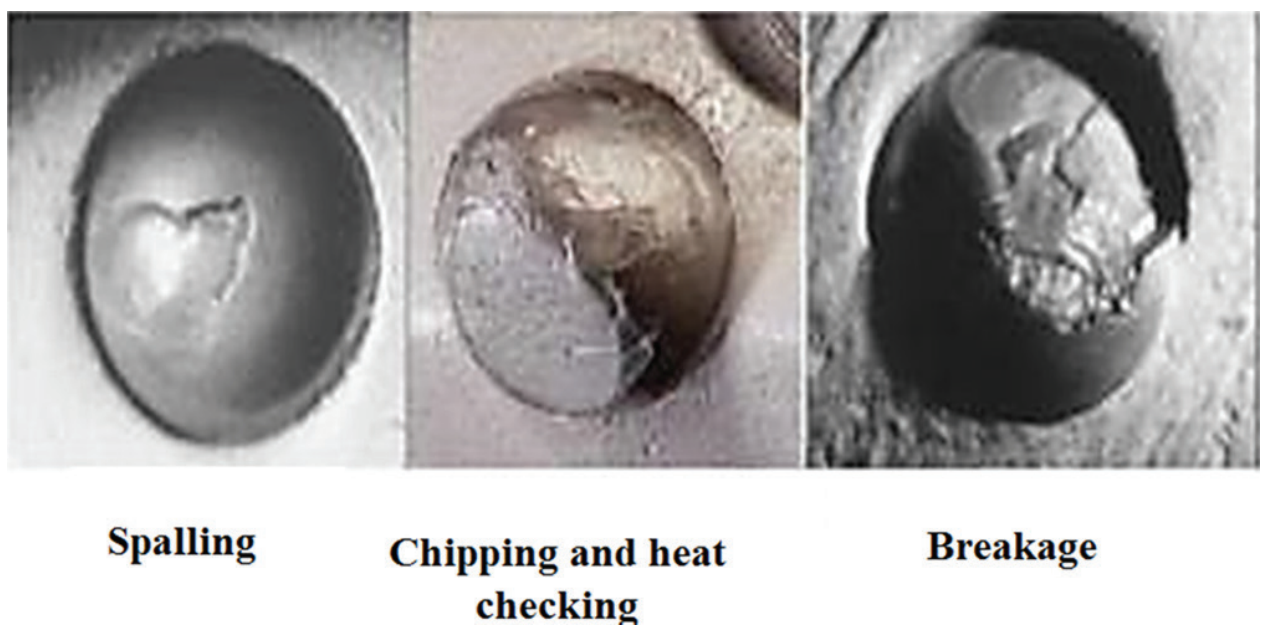

Fig. 1. Typical failure modes of PCD inserts for rock drill bit (Fang, et al., 2001).
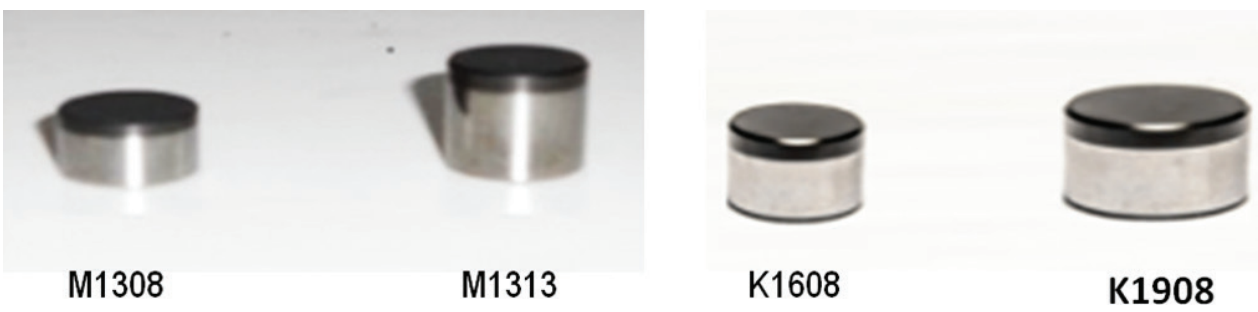

Fig. 2. Oil polycrystalline diamond compact cutters manufactured by two different manufacturers. 

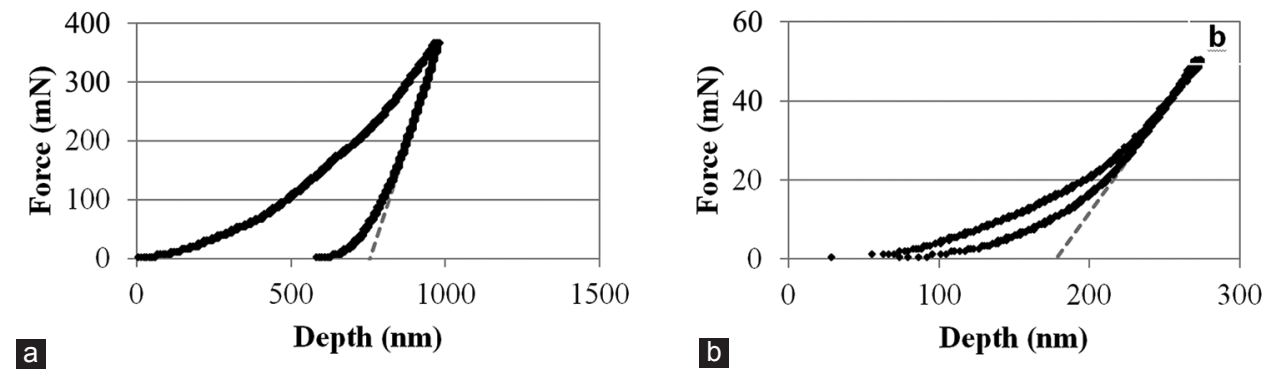

Fig. 3. (a) Applied force against displacement for tungsten carbide-cobalt at fixed load of $350 \mathrm{mN}$, (b) load versus the indentation depth for the polycrystalline diamond compact-Co at fixed load of $50 \mathrm{mN}$.

that the hardness and Young's modulus of ceramic before and after were nearly the same and this indicated that the tip of the nanoindenter was intact and not damaged.

The previous reported value of the hardness and Young's modulus of PDC was within the range 50-60 GPa and 776$925 \mathrm{GPa}$, respectively, depending on the diamond grain size and the percentage of the cobalt binder which varied from $5 \%$ to $20 \%$ (Dubrovinskaia, 2006), (Osipov, et al., 2010), and Ndlovu (2009). To prevent large fluctuation in the measurement of material properties, microindentation experiments were carried out. A series of microindentation tests were performed on the diamond and the substrate layers of the PDC samples using INSTRON 5566 equipment using Vickers indenter at various loads. Microindentations on diamond coatings require a highly polished test surface to discard the effect of the asperities that might cause undesirable results such as producing unclear indents. Fig. 4 illustrates the indents left after using Vickers probe on the substrate layer of sample K1908 after applying a load of $50 \mathrm{~N}$. Table II demonstrates the average results of the hardness and Young's modulus determined from micro- and nano-indentation tests on both layers of the PDC samples. It is obvious that the standard deviation of the nanoindentation results is much higher than that of microindentation due to the aforementioned reason.

Fracture toughness was determined from the microindentation tests for the diamond and the substrate layers of the PDC inserts.

\section{B. Microstructural properties and the cobalt content of PDC cutters}

This part of the work is carried out to study the effect of the microstructural properties of the cutters on the mechanical properties of the diamond and substrate layers. The microstructural properties have been characterized by energy dispersive X-ray (EDX) images. The particles size of the coating (diamond) and the substrate (tungsten-carbide) has been quantified by the Image $J$ software, whereas the weight percentage of the binder (cobalt) in the PDC samples has been determined from EDX element table content and from longitudinal measurement of the binder (cobalt) across the interface between the diamond and the substrate layers using (EDX-Quantline).

Backscattered detector (BSD) images are used for displaying the best resolution of the particle distribution

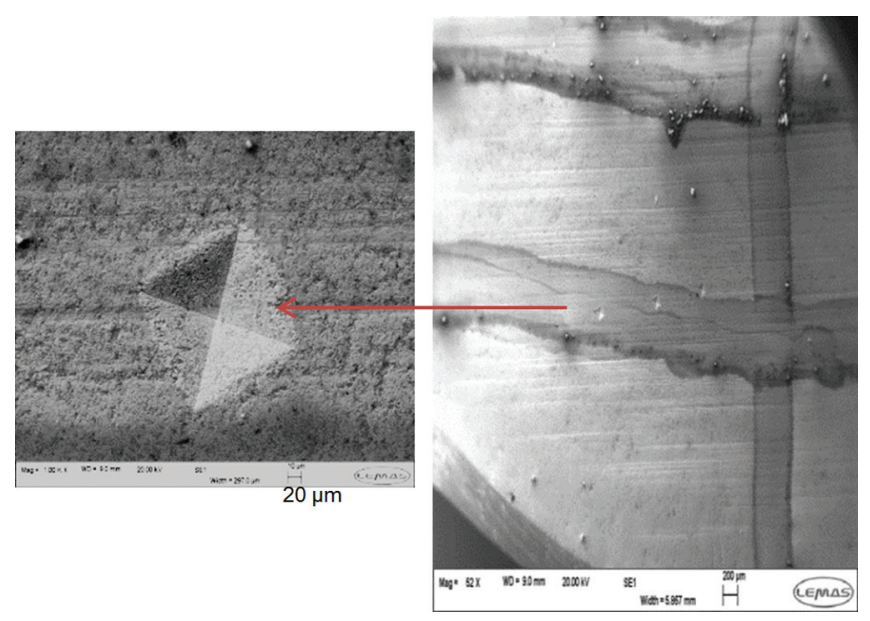

Fig. 4. Vickers imprints on the substrate of sample K190 after applying $50 \mathrm{~N}$ load.

compared to normal scanning electron microscope (SEM) images. EDX maps are used for determining the cobalt content in the diamond and the substrate layers of the PDC cutters.

The circular equivalent diameter of the diamond particles and substrate is determined by image $\mathrm{J}$ software after analyzing the BSD images. It should be noted that major drawback of this technique is that the size characteristics are based on two-dimensional (2D) image analysis and may not represent the particles third dimension.

Fig. 5 (top) shows the diamond particles (black areas) embedded in the cobalt binder (white areas) for samples M1313 (a) and K1908 (b). The particle size distribution of the diamond grains of samples M1313 and K1908 is shown in Fig. 5 (bottom).

Fig. 6 (top) illustrates the tungsten-carbide particles embedded in cobalt (blue) for (a) sample M1313 and (b) sample K1908, whereas Fig. 6 (bottom) demonstrates the tungsten-carbide grain size distribution for (c) specimen M1313 and (d) sample K1908.

The cobalt content represented as weight percentage is determined from EDX element content at various spectrum areas of the diamond and substrate layers, and then, averaged results with standard deviation are presented in Table III.

To summarize the microstructural obtained results, Table III shows the microstructural properties of two PDC samples from different manufacturers. 

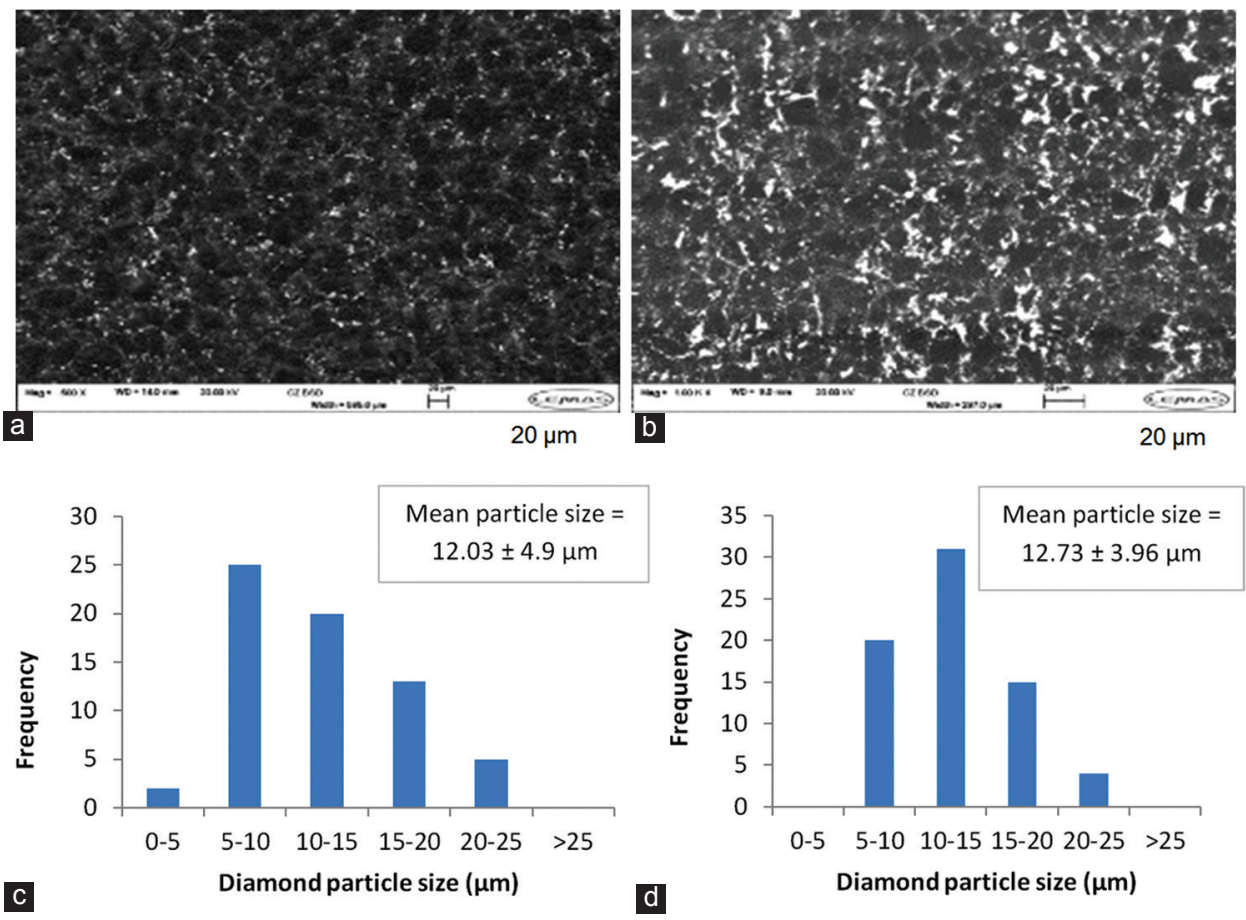

Fig. 5. (Top) Backscattered detector images. (a) sample M1313, (b) sample K1908 of the diamond layer displaying the diamond grains (black) and the cobalt (white), (bottom) diamond particle size distribution of sample M1313, and (c) sample K1908 (d).

TABLE II

MECHANICAL PROPERTIES OF PDC SAMPLES FROM MICRO- AND NANO-INDENTATION TESTS

\begin{tabular}{|c|c|c|c|c|}
\hline PDC sample & Vickers hardness (GPa) & Yong's modulus (GPa) & Fracture toughness $\left(\mathrm{MPa} \cdot \mathrm{m}^{1 / 2}\right)$ & Layer \\
\hline M1313 (Nano indentation) & $16.69 \pm 6.59$ & $487.96 \pm 161.18$ & N/A & Substrate \\
\hline M1313 (Microindentation) & $13.072 \pm 0.066$ & $516.943 \pm 2.169$ & $11.908 \pm 2.152$ & Substrate \\
\hline K1908 (Microindentation) & $12.564 \pm 0.257$ & $514.344 \pm 0.877$ & $12.277 \pm 2.146$ & Substrate \\
\hline M1313 (Microindentation) & $50.85 \pm 0.912$ & $864.534 \pm 0.986$ & $9.13 \pm 1.219$ & Diamond \\
\hline K1908 (Micro indentation) & $46.092 \pm 0.754$ & $855.63 \pm 4.474$ & $9.641 \pm 1.064$ & Diamond \\
\hline
\end{tabular}

PDC: Polycrystalline diamond compact

TABLE III

STRUCTURAL PROPERTIES OF PDC INSERTS FROM DIFFERENT MANUFACTURERS

\begin{tabular}{lcc}
\hline \hline Microstructural properties & \multicolumn{2}{c}{ PDC samples } \\
\cline { 2 - 3 } & M1313 & K1908 \\
\hline Diamond particle size $(\mu \mathrm{m})$ & $12.03 \pm 4.9$ & $12.73 \pm 3.96$ \\
& $\min <4.52$ & $\min <6.9$ \\
& $\max >23.25$ & $\max >23.9$ \\
WC particle size $(\mu \mathrm{n})$ & $2.52 \pm 2.11$ & $2.3 \pm 1.69$ \\
& $\min <0.38$ & $\min <0.3$ \\
& $\max >8.23$ & $\max >7.73$ \\
Co wt. \% (in (diamond) & $3.26 \pm 0.5$ & $4.4 \pm 0.51$ \\
Co wt. \% (in WC-Co) & $7.37 \pm 0.39$ & $8.82 \pm 0.32$ \\
\hline \hline
\end{tabular}

PDC: Polycrystalline diamond compact

Increasing the cobalt content for a given particle size causes the fracture toughness to increase, but it usually reduces the hardness (Bellin, et al., 2010c). It is also reported that fine tungsten carbide grain size and a low level of cobalt content lead to higher hardness and good wear resistance, whereas coarse particles and high cobalt content produce low hardness and high wear rate (Mori, et al., 2003; Ndlovu,
2009). Yahiaoui, et al. (2013) stated that the grain size and the content of cobalt are the most significant parameters of PDC cutters as high wear rate is associated with large particle size. Bellin, et al. (2010b) reported that the increasing the cobalt content in the diamond layer and the substrate will increase the fracture toughness, whereas the wear resistance increases with lower cobalt content.

The particle size of the substrate layer of samples M1313 and K1908 is around 2.3-2.5 $\mu \mathrm{m}$, whereas the cobalt content in the substrate of sample M1313 is slightly lower than sample K1908. Accordingly, it is expected from these results that the abrasion (wear) resistance of sample M1313 is slightly greater than sample K1908, whereas sample K1908 has a better fracture toughness than sample M1313 (as can be seen from Table II).

The hardness of the diamond layer of sample M1313 found to be greater than the hardness of the sample K1908 as shown in Table II. This is mainly due to a lower level of binder content $(3.26 \%)$ in sample M1313 compared to sample K1908 (4.4\%), whereas the grain sizes are not that different. 

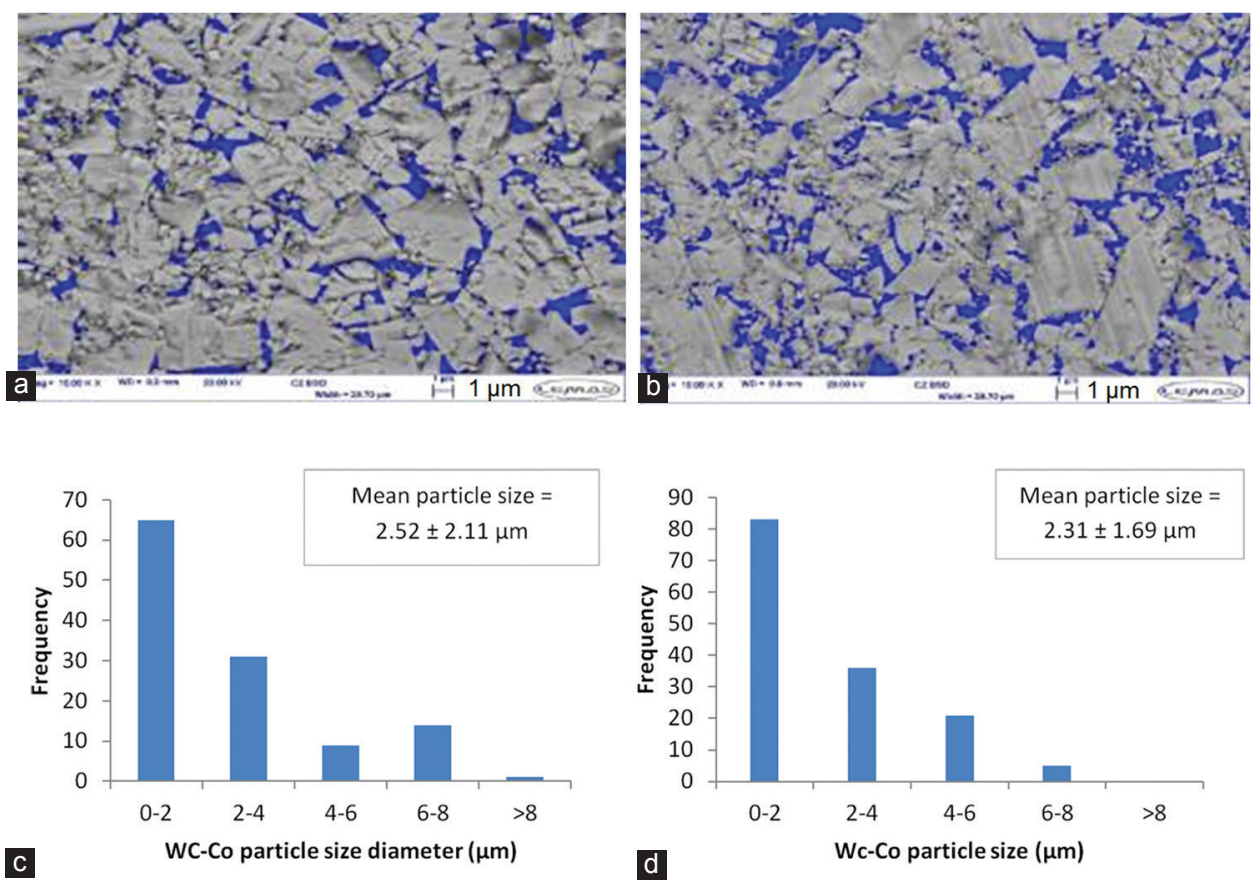

Fig. 6. (Top) BSD images (a) sample M1313, (b) sample K1908 of the substrate layer displaying the tungsten-carbide particles (gray) and the cobalt (blue), (bottom) substrate grain size distribution, (c) Specimen M1313, and (d) specimen K1908.

For the substrate layer, the hardness of the tungstencarbide layer of sample M1313 is found to be higher than sample K1908 as shown in Table II, and this is attributed to the difference in the cobalt content of the substrate for the two PDC cutters. The cobalt mass weight percentage in sample M1313 is near 7\%, whereas sample K1908 has cobalt content of about $9 \%$. The mean grain size of samples M1313 and K1908 is very similar.

\section{Microscratch testing}

The work presented in this section is focused on quantifying the wear of PDC cutters and the effect of their mechanical properties on the extent of wear. The volume of wear for the PDC cutters was determined experimentally using microscratch and later from nanoscratch tests on different layers of PDC cutters, that is, the diamond layer and tungsten-carbide (substrate layer) by implementing an approach based on the geometry of the removed material after the tests. In addition, this section illustrates how the experimental wear is compared to the predicted wear based on current approaches in the literature. Various wear models are evaluated for micro- and nano-scratch tests on both layers of the PDC samples: Substrate and diamond.

The scratch caused by a sharp indenter produces abrasion wear that would be crucially important for wear mechanism and evaluation. A series of microscratch tests were carried out by applying various loads on the surface of the material and moving the probe to a sufficient sliding distance to produce a scratch. Scratch length and width are the most points of interest for evaluating the wear of the material.

The microscratch tests were performed using an INSTRON 5566 mechanical testing machine and a diamond indenter.
Vickers and spheroconical diamond indenters were used during the microscratch tests on both layers of the PDC samples. The obtained microscratches were examined by SEM, EDX, 2D Talysurf, and three-dimensional interferometer to determine the scratches width and depth as well as for analytical study.

A series of microscratch tests using a Vickers indenter were conducted on both layers of the PDC specimens under various loads. The samples were mounted on an anvil that has a manual controller to alter the sliding distance, whereas the applied load was kept constant. The substrate of the PDC sample was scratched using loads ranging 100-300 N. Measured wear from microscratch tests was compared to the predicted wear based on models in the literature.

The height of the scratch is measured by the $2 \mathrm{D}$ profilemeter. Careful measurements were carried out using Ultra Precision Talysurf PGI800 with a resolution up to $0.8 \mathrm{~nm}$.

The volume of wear $\left(V_{w}\right)$ is determined experimentally from the geometry of the removed material using the following equation:

$$
V_{w}=\frac{w_{s} \cdot h_{s}}{2} X
$$

Where $w_{s}$ is the width of the scratch and is measured by image analysis of SEM records, $X$ is the sliding distance, and $h_{s}$ is the height of the scratch.

Special care was taken in scratching the surface of the diamond layer, where low loads $10 \mathrm{~N}-20 \mathrm{~N}$ were applied to avoid wrecking the tip of the indenter due to the high resistance of the material surface and a high degree of asperities.

Measured wear form microscratch test is compared to the predicted wear based on approaches in the literature by Rabinowicz (1996), Hutchings (1992), and Ning and 

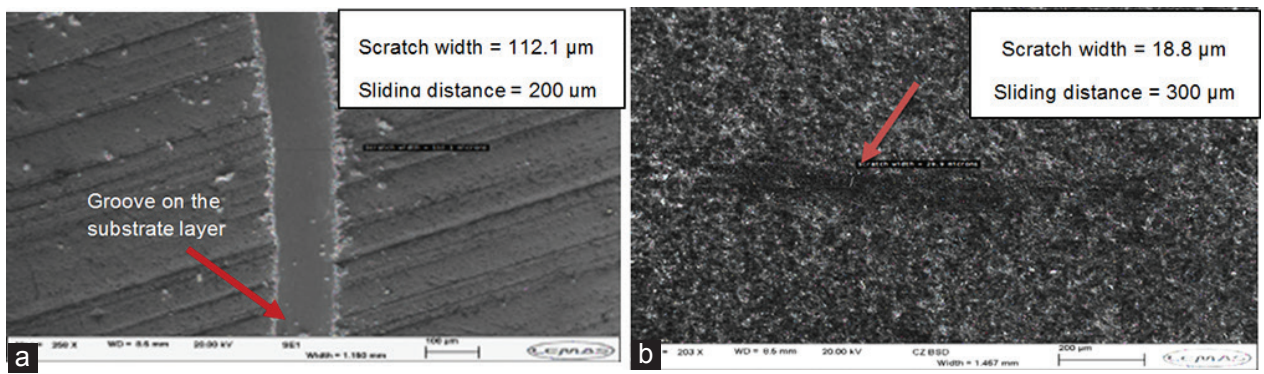

Fig. 7. (a) Groove obtained using a spheroconical indenter at $50 \mathrm{~N}$ load on WC-Co, (b) scratch obtained using a spheroconical layer at $10 \mathrm{~N}$ on the diamond layer.

Ghadiri (2006) as described by Equations (2), (3), and (4), respectively:

$$
\begin{gathered}
V_{w}=\frac{F \cdot \tan (\beta) \cdot X}{\pi \cdot H} \\
V_{w}=\frac{2 F \cdot X}{\pi \cdot H \cdot \tan (\alpha)} \\
V_{w}=\frac{0.07 F^{\frac{5}{4}}}{K_{c} \pi^{\frac{5}{4}} H^{\frac{1}{4}}}\left(2 L+\frac{\pi^{\frac{1}{4}} H^{\frac{1}{4}} F^{\frac{3}{4}}}{17 \cdot 1 K_{c}}\right)
\end{gathered}
$$

Where $F$ is the applied load (N), $X$ and $L$ are the sliding distances $(\mathrm{m}), \beta$ is the abrasion angle (degrees), $H$ is the hardness of the softest or abraded material $\left(\mathrm{N} / \mathrm{m}^{2}\right), \alpha$ is the half angle of the abrasive particle (degrees), and $K_{c}$ is the fracture toughness of the material (MPa.m ${ }^{1 / 2}$ ).

Due to the high risk of wrecking the diamond indenter, especially when conducting the micro- and nano-scratch testing on the diamond layer of the PDC samples, additional scratch tests were performed using spheroconical indenter. The use of a spherical tip of the probe is an effective way to reduce the risk of breakage as compared to the use of sharp indenters, particularly when scratching hard coatings (Beake, et al., 2011).

Fig. 7a shows the produced groove after applying $50 \mathrm{~N}$ on the tungsten-carbide-cobalt (WC-Co) layer of sample K1908 using spheroconical indenter. The scratch width and sliding distance were $112.1 \mu \mathrm{m}$ and $200 \mu \mathrm{m}$, respectively, whereas Fig. $7 \mathrm{~b}$ illustrates a scratch obtained after applying $10 \mathrm{~N}$ on the diamond layer of sample K1908. The scratch width and sliding distance were $29.9 \mu \mathrm{m}$ and $2300 \mu \mathrm{m}$, respectively. The SEM images showed that the debris resulted from the ploughing action due to the microscratching of sample K1908.

The wear produced using spheroconical indenter from microscratch and later nanoscratch test is determined from the following equation which is found to quantify the wear volume of the x-track as follows (CSM Ltd., 2002):

$$
V_{w}=A_{\text {segment }} * L
$$

Where $A_{\text {segment }}$ is the area of the circular segment as seen from Fig. 8 and could be determined from the following equation:

$$
A_{\text {segment }}=\frac{1}{2} * R^{2} *[\theta-\sin \theta]
$$

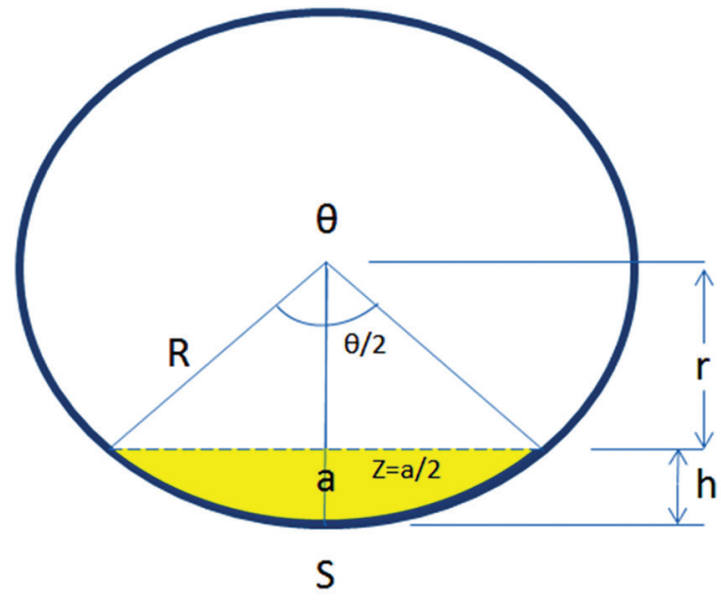

Fig. 8. Sketch of the circular segment of the conical tip that indents the diamond layer.

Where $\theta$ is the angle opposing the segment of the circle, and it can be computed from Equation (8):

$$
\theta=2 \cos ^{-1}\left(1-\frac{h}{R}\right)
$$

Where $R$ is the radius of the circle and $h$ is the residual depth of the micro- or nano-scratch as shown in Fig. 8.

\section{Nanomechanical|testing}

Nanomechanical testing is a technique that has been used recently for the evaluation of mechanical failure of ceramics and notably the nano-tribological measurements. Nanoscratch testing approach has a preference as it can overcome problems regarding the wreckage of the indenters and the contribution of the machine compliance and surface roughness of the sample (Beake, et al., 2006; 2009; 2013).

In this study, the multiscratch test was conducted on the substrate and the diamond layers of two PDC cutters from different manufactures under specific conditions of fixed load at $500 \mathrm{mN}$ after $200 \mu \mathrm{m}$ scratch length, loading rate of $20 \mathrm{mN} / \mathrm{s}$, and scratch rate of $10 \mu \mathrm{m} / \mathrm{s}$. The Micro Materials Nano Test device has been used for the nanoscratch test. The tip of the spheroconical indenter has a radius of $25 \mu \mathrm{m}$. The specimen's surface has been polished before launching the nanoexperiments to minimize surface asperities. 


\section{RESUlts AND DiscusSION}

The experimental wear as a result of the microscratch tests using Vickers indenter was compared to the predicted wear from various models as shown in Fig. 9.

It is clearly seen from Fig. 9 that the predicted wear from Hutchings model is the closest to the experimental wear based on Equation (1). Rabinowicz model gave lower wear values than the experimental wear, whereas Ning and Ghadiri model displays higher values than the experimental one. This might be due to the influence of fracture toughness on the equation of Ning and Ghadiri. This finding is applicable for both layers of the PDC Diamond when Vickers indenter was used to create microscratches on both layers of the PDC inserts.

The obtained wear from nanoexperimental scratch test together with those of microscratch test of the substrate layer for samples K1908 and M1313 is shown in Fig. 10a. It can be seen that the wear of substrate layer for sample K1908 is slightly higher than that of sample M1313.

Similarly, for the diamond layer, wear results obtained from micro- and nano-scratch tests were plotted in Fig. $10 \mathrm{~b}$. Similarly, the wear of the diamond layer of sample K1908 is slightly higher than that of sample M1313.
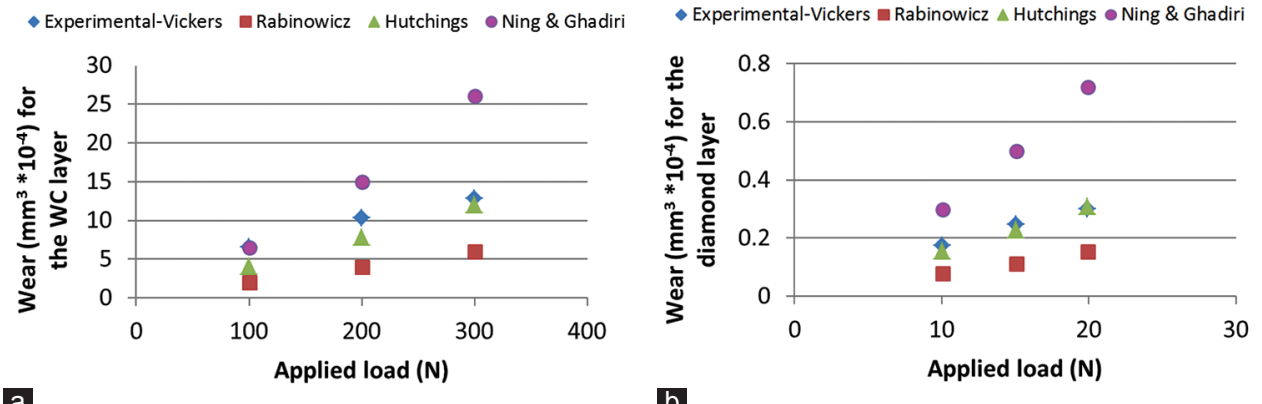

Fig. 9. (a) Wear by various models for the tungsten-carbide layer for sample M1313, (b) wear for various models of wear for the diamond layer for sample M1313.

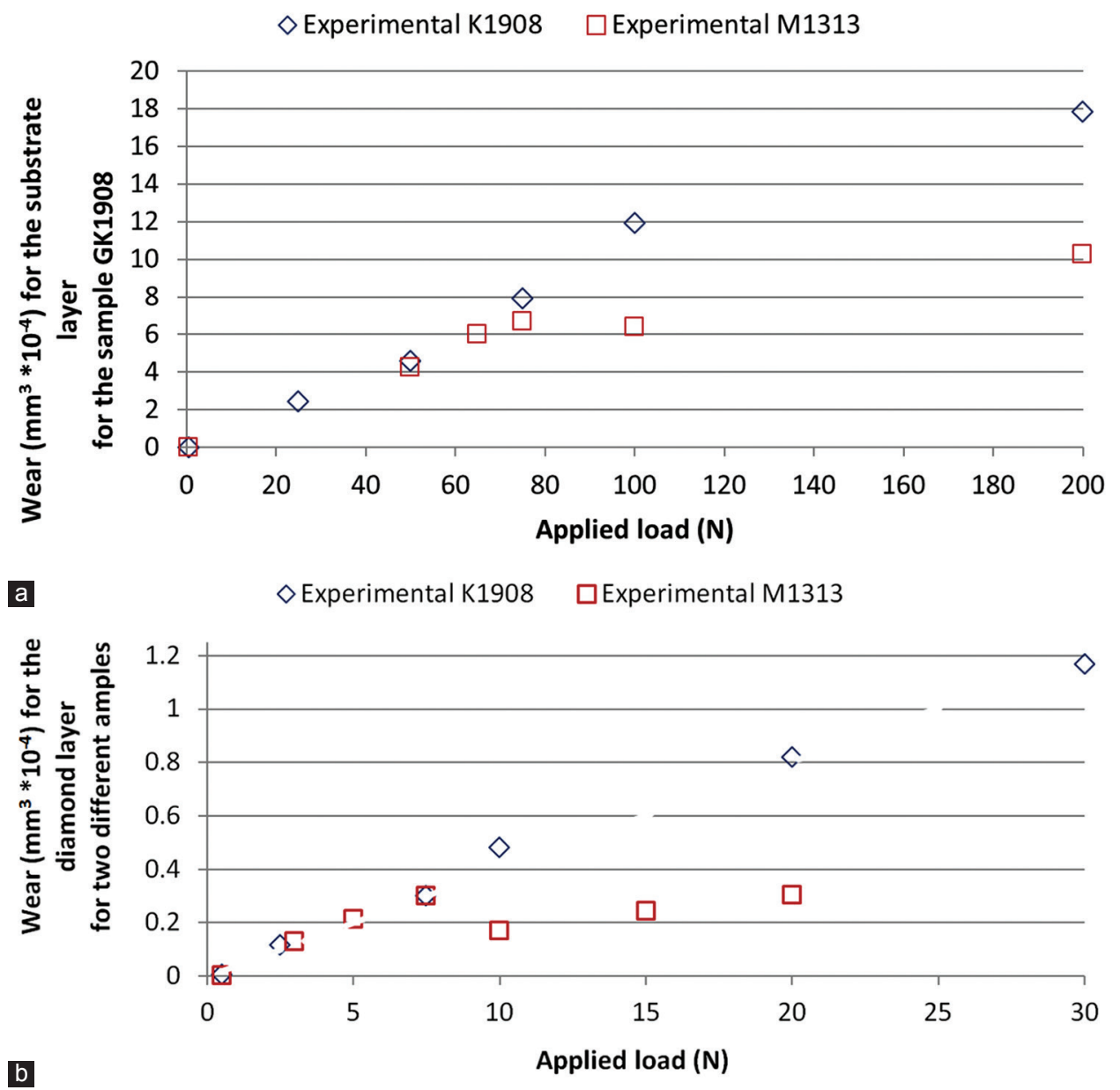

Fig. 10. (a) Experimental wear for the substrate layer of samples K1908 and M1313, (b) experimental wear for the diamond layer of samples K1908 and M1313. 


\section{CONCLUSIONS}

The material properties and wear tendencies of both layers (diamond and substrate) of two PDC bit cutters from different manufacturers (samples M1313 and k1908) were studied using micro- and nano-test techniques. Hardness of the diamond layer of sample M1313 found to be greater than that of the sample K1908. This is mainly due to a lower level of cobalt content in sample M1313 (3.26\%) compared to that of sample K1908 (4.4\%) as well as slightly smaller grain size of sample M1313 $(12.03 \mu \mathrm{m})$ compared to that of sample K1908 (12.73 $\mu \mathrm{m})$.

For the substrate layer, the hardness sample M1313 is found to be higher than that of sample K1908 attributed mainly to the difference in the cobalt content of the substrate of the two PDC cutters. In this work, the wear of PDC samples has also been assessed using micro- and nano-scratch techniques. The tests were carried out on both layers of PDC samples. The results suggest that sample M1313 has higher wear resistance than sample K1908. This is attributed to a higher hardness of sample M1313 as compared to sample K1908 which is a result of different binder (cobalt) content and grain sizes.

Furthermore, the quantitative results suggest that wear of each sample is proportional to the applied force and sliding distance and inversely to the hardness of the material, according to the model of Archard.

It was shown that all the data for both samples can be unified on a curve considering the three parameters mentioned above (load, sliding distance, and hardness), suggesting that wear tendency of samples could be predicted based on the mechanical properties, notably hardness.

The findings of this study could be applied to various types of PDC cutters from different manufacturers to evaluate the intensity of wear as a quality index rather than using the previous traditional abrasion tests.

\section{Nomenclature}

$A_{\text {segment }}$ : Area of the circle's segment $\left(\mu \mathrm{m}^{2}, \mathrm{~nm}^{2}\right)$

Co: Cobalt (binder)

$C E D$ : Circular equivalent diameter

$F$ : Applied load $(\mathrm{mN}, \mathrm{N})$

$F(A)$ : Function in Archard equation

$H, H_{m}$ : Hardness of the material $\left(\mathrm{N} / \mathrm{m}^{2}, \mathrm{GPa}\right)$

$H_{a}$ : Hardness of the abrasive $\left(\mathrm{N} / \mathrm{m}^{2}, \mathrm{GPa}\right)$

$H$ : Residual depth $(\mathrm{nm}, \mu \mathrm{m})$

$h_{s}$ : Scratch height $(\mu \mathrm{m})$

$K$ : Constant for the system or wear coefficient

$K_{C}$ : Fracture toughness of the material (MPa.m ${ }^{1 / 2}$ )

$N$ : Index of incremental depth and sliding distance

$R$ : Radius of the circle $(\mathrm{nm}, \mu \mathrm{m})$

$r$ : Height of the triangle $(\mathrm{nm}, \mu \mathrm{m})$

SHN: Scratch hardness number (GPa)

$V_{w}$ : Volume of wear $\left(\mu \mathrm{m}^{3}, \mathrm{~mm}^{3}\right)$

$W C$ : Tungsten-carbide

$w_{s}:$ Scratch width $(\mu \mathrm{m})$

$X, L$ : Sliding distance $(\mu \mathrm{m})$

$\alpha$ : Half angle of the abrasive particle (degrees)

$\beta$ : Abrasion angle (degrees)

$\theta$ : Angle opposing the segment of the circle (degree).

\section{ACKNOWLEDGMENTS}

Special word of thanks is given to Dr. Umair Zafar (Postdoc.) in Ghadiri group for his assistance in carrying out nanoscratch tests at the Institute of Particle Science and Engineering at the University of Leeds, UK. Furthermore, the authors must not forget the precious information given by Prof. Ben Beake (Micromaterials, UK) for his help regarding the nanoscratch test.

\section{REFERENCES}

Archard, J.F., 1953. Contact and Rubbing of Flat Surfaces. Journal of Applied Physics, 24(8), pp.981-988.

Beake, B.D., Vishnyakov, V.M., Valizadeh, R. and Colligon, J.S., 2006. Influence of mechanical properties on the nano-scratch behaviour of hard nanocomposite TiN/Si 3 N 4 coatings on Si. Journal of Physics D: Applied Physics. 39(7), pp.1392-1397.

Beake, B.D., Goodes, S.R. and Shi, B., 2009. Nanomechanical and nanotribological testing of ultra-thin carbon-based and MoST films for increased MEMS durability. Journal of Physics D: Applied Physics. 42(6), pp.065301.

Beake, B.D., Harris, A.J. and Liskiewicz, T.W., 2013. Review of recent progress in nano-scratch testing. Tribology - Materials, Surfaces and Interfaces. 7(2), pp.87-96.

Beake, B.D., Shi, B. and Sullivan, J.L., 2011. Nanoscratch and nanowear testing of TiN coatings on M42 steel. Tribology-Materials, Surfaces and Interfaces. 5(4), pp.141-147.

Bellin, F., Dourfaye, A., King, W. and Thigpen, M., 2010a. The current state of PDC bit technology. World Oil. 9, pp.53-58.

Bellin, F., Dourfaye, A., King, W. and Thigpen, M., 2010b. The current state of PDC bit technology. World Oil, 2010, pp.41-46.

Bellin, F., Dourfaye, A., King, W. and Thigpen, M., 2010c. The current state of PDC bit technology. World Oil, 2010, pp.67-71.

Couvy, H., Lahiri, D., Chen, J., Agarwal, A. and Sen, G., 2011. Nanohardness and Young's modulus of nanopolycrystalline diamond. Scripta Materialia. 64(11), pp.1019-1022.

CSM Instruments., 2002. Overview of Mechanical Testing Standards. Available from: http://www.csm-instruments.com/en/webfm_send/42. [Last accessed on 2015 Jun 29].

Dubrovinskaia, N., Dub, S., Dubrovinsky, L., 2006. Super wear resistance of aggregated diamond nanorods. Nano Lett. 6(4), pp.824-826.

Fang, Z., Griffo, A., White, B., Belnap, D., Hamilton, R., Portwood, G.P., Cox, P., Hilmas, G. and Bitler, J., 2001.Chipping resistant polycrystalline diamond and carbide composite materials for roller cone bits. In: The SPE Annual Technical Conference and Exhibition. New Orleans, Louisiana. USA.

Geoffroy, H., Minh, D.N., Bergues, J. and Putot, C., 1999. Interaction between Rock and Worn PDC Bit: Theory and Experiments. In: The $9^{\text {th }}$ International Society for Rock Mechanics Congress. Paris. France.

Hutchings, I.M., 1992. Tribology: Friction and Wear of Engineering Materials. Edward Arnold, London.

Mori, N., Moriguchi, H., Ikegaya, A., Shioya, Y. and Ohbi, K., 2003. Development of Highly Durable Materials for Drilling Hard and Abrasive Rocks. In: The SPE Asia Pacific Oil and Gas Conference and Exhibition. 15-17 April 200, Jakarta. Indonesia.

Mouritz, A.P. and Hutchings, I.M., 1991. The Abrasive Wear of Rock Drill Bit Materials. Society of Petroleum Engineers, Paper SPE 24222.

Ndlovu, S., 2009. The wear properties of Tungsten Carbide-Cobalt Hardmetals from the Nanoscale up to the Macroscopic Scale. A PhD Dissertation Submitted 
to the Materials Science and Engineering, University of Erlangen-Nuremberg, Germany.

Ning, Z. and Ghadiri, M., 2006. Distinct element analysis of attrition of granular solids under shear deformation. Chemical Engineering Science. 61(18), pp.5991-6001.

Osipov, A.S., Bondarenko, N.A., Petrusha, I.A. and Mechnik, V.A., 2010. Drill bits with thermostable PDC inserts. Diamond Tooling Journal. 70(625), pp.31-34. Available from: http://www.dtj-online.com/userfiles/file/Vol70Num625_31-34. pdf. [Last accessed on 2012 Sep 16].

Rabinowicz, E., 1996. Friction and Wear of Materials. $2^{\text {nd }}$ ed. John Wiley and Sons, Toronto, ON.
Richardson, R.C., 1968. The wear of metals by relatively soft abrasives. Wear. 11(4), pp.245-275.

Sumiya, H. and Irifune, T., 2004. Indentation hardness of nano-polycrystalline diamond prepared from graphite by direct conversion. Diamond and Related Materials. 13(10), pp.1771-1776.

Tze-Pin, L., Hood, M., Cooper, G. and Xiaohong, L., 1992. Wear and failure mechanisms of polycrystalline diamond compact bits. Wear. 156(1), pp.133-150.

Yahiaoui, M., Gerbaud, L., Paris, J.Y., Denape, J. and Dourfaye, A., 2013. A study on PDC drill bits quality. Wear. 298-299, pp.32-41.

Zacny, K. 2012. Fracture and fatigue of polycrystalline-diamond compacts. SPE Drilling and Completion 27, pp.145-157. 